\title{
DYNAMIC CHANNEL RESERVATION SCHEME FOR HANDOFF PRIORITIZATION IN WIRELESS CELLULAR NETWORKS
}

\author{
Mohammad M. Zahra \\ Electrical Engineering Department, Faculty of Engineering, AL-AZHAR \\ University, Cairo, Egypt \\ E-mail: \{mzahra_2001@yahoo.com; mmzahra@hotmail.com\}
}

(Received April 9, 2005 Accepted May 31, 2005)

\begin{abstract}
In wireless cellular networks, in order to ensure that ongoing calls are not dropped while the users roam among cells, handoff calls may be admitted with a higher priority as compared to new calls. One way to improve system performance of cellular networks is to use efficient handover schemes when users move between cells. In this paper, a new dynamic scheme, called Dynamic Channel Reservation (DCR) is proposed and evaluated to improve the utilization of wireless network resources. The required GoS of handoff calls are guaranteed. Simulation results show that the proposed scheme improves handoff calls blocking probability in expense of an acceptable blocking probability of new calls.
\end{abstract}

KEYWORDS: cellular networks, handoff, dynamic channel reservation.

\section{INTRODUCTION}

In cellular systems, service area is divided into small cells. Cells are defined by a circular region that ranges from few hundred meters to a few kilometers in radius. An improvement property of the network is that a user would change its access points several times. This fact causes technical problems in which fair bandwidth sharing between handoff calls and new calls is required [1]. As mobile user moves from one cell to another, its ongoing call is handed-off from the old cell to a new cell. This requires that the new cell accommodate the call. Since dropping a handoff call is more annoying than blocking a new call from user's perspective, handoff calls should be given higher priority than new calls [2]. It has been shown that method by which handoff is achieved has a significant impact on the network's performance. The native channel assignment strategy is to treat the handoff and new calls equally [3].

Much work has been done on handoff prioritization in wireless cellular systems [4-8]. There are two popular strategies for prioritizing handoff calls: the Guard Channel strategy and the handoff Queuing strategy. The Guard Channel strategy decreases the handoff dropping probability by reserving a fixed number of channels exclusively for handoff calls. New calls will be blocked if the number of the idle channels is equal to or less than the number of guard channels, while handoff calls can be served until all the channels are occupied. Handoff Queuing strategy is a way of delaying handoff calls due to the temporary unavailability of channels [9]. 
In this paper a new dynamic channel reservation scheme (DCR) is proposed, that guarantees the required dropping probability of handoff calls while keeping the blocking probability of new calls as low as possible.

\section{SIMULATION MODEL}

A simulation model is constructed to evaluate the performance of the DCR scheme. This simulation model includes system model and traffic model.

\section{A. System Model}

For simplicity, a one-dimensional array of cells is considered in this model. In order to avoid unwanted boundary effects like mobile leaving the system, it is assumed that cells are arranged in the form of a hexagon which is commonly used in the simulation of wireless cellular systems. There are overlapping areas between adjacent cells.

\section{B. Traffic Model}

In simulation model, homogeneous calls are considered, and it is assumed that each mobile station needs only one channel per call. New and handoff calls generation in the system follows a Poisson process with an average arrival rates $\lambda_{i}$ and $\gamma_{i}$ calls/sec, respectively. The call holding time follows an exponential distribution with mean $1 / \mu$ $=120 \mathrm{sec}$.

A cellular network consisting of $M$ clusters is considered. Each cluster consists of $\mathrm{N}_{\mathrm{m}}$ cells, $\mathrm{m}=1,2,3, \ldots, \mathrm{M}$. Frequency channels $\mathrm{c}_{\mathrm{i}}$ are assigned to a cell $\mathrm{i}, \mathrm{i}=1,2,3, \ldots$. , $\mathrm{N}_{\mathrm{m}}$. It is assumed that a cell $\mathrm{i}$ consists of ordinary channels $\mathrm{x}_{\mathrm{i}}$, which carry both types of calls and guard channels $y_{i}$, which carry only the handoff calls. New call attempts are blocked if $\mathrm{x}_{\mathrm{i}}$ channels are occupied, while handoff call attempts are assigned guard channels. Handoff calls attempts are dropped only when all channels are occupied.

This system can be modeled as a Markov process and probability $\left(\mathrm{P}_{\mathrm{i}}\right)$ can be calculated as following [7].

$$
\mathrm{P}_{\mathrm{i}}(\mathrm{j})= \begin{cases}\frac{a_{\mathrm{i}}^{\mathrm{j}}}{\mathrm{j} !} P_{i}(0) & 0 \leq \mathrm{j} \leq \mathrm{x}_{\mathrm{i}} \\ \frac{a_{i}^{x_{i}} \mathrm{~b}_{\mathrm{i}}^{\mathrm{j}-\mathrm{x}_{\mathrm{i}}}}{\mathrm{j} !} \mathrm{P}_{\mathrm{i}}(0) & \mathrm{x}_{\mathrm{i}} \leq \mathrm{j} \leq c_{i}\end{cases}
$$

Where

$$
\begin{aligned}
& a_{i}=\frac{\lambda_{i}+\gamma_{i}}{\mu} \\
& \mathrm{b}=\frac{\gamma_{\mathrm{i}}}{\mu}
\end{aligned}
$$




$$
\mathrm{P}_{\mathrm{i}}(0)=\frac{1}{\left(\sum_{j=0}^{x_{i}-1} \frac{a_{\mathrm{j}}^{\mathrm{j}}}{\mathrm{j} !}+a_{\mathrm{i}}^{\mathrm{x}_{\mathrm{i}}} \sum_{\mathrm{j}=\mathrm{x}_{\mathrm{i}}}^{\mathrm{c}_{\mathrm{i}}} \frac{\mathrm{b}_{\mathrm{i}}^{\mathrm{j}-\mathrm{x}_{\mathrm{i}}}}{\mathrm{j} !}\right)}
$$

The blocking probability of new call attempts, $\mathrm{BN}_{\mathrm{i}}\left(\mathrm{x}_{\mathrm{i}}, \mathrm{y}_{\mathrm{i}}\right)$ is given by:

$$
\begin{aligned}
\mathrm{BN}_{\mathrm{i}}\left(\mathrm{x}_{\mathrm{i}}, \mathrm{y}_{\mathrm{i}}\right)=\sum_{\mathrm{j}=\mathrm{x}_{\mathrm{i}}}^{\mathrm{x}_{\mathrm{i}}+\mathrm{y}_{\mathrm{i}}} \mathrm{P}_{\mathrm{i}}(\mathrm{j}) \\
=\frac{\left[\frac{a_{\mathrm{i}}^{\mathrm{x}_{\mathrm{i}}}}{\mathrm{x}_{\mathrm{i}} !}+a_{\mathrm{i}}^{\mathrm{x}_{\mathrm{i}}} \sum_{\mathrm{j}=1}^{\mathrm{y}_{\mathrm{i}}} \frac{\mathrm{b}_{\mathrm{i}}^{\mathrm{j}}}{\left(\mathrm{x}_{\mathrm{i}}+\mathrm{j}\right) !}\right]}{\left(\sum_{j=0}^{x_{i}} \frac{a_{i}^{j}}{\mathrm{j} !}+a_{\mathrm{i}}^{\mathrm{x}_{\mathrm{i}}} \sum_{\mathrm{j}=1}^{\mathrm{y}_{\mathrm{i}}} \frac{\mathrm{b}_{\mathrm{i}}^{\mathrm{j}}}{\left(\mathrm{x}_{\mathrm{i}}+\mathrm{j}\right) !}\right)}
\end{aligned}
$$

The blocking probability of handoff call attempts, $\mathrm{BH}_{\mathrm{i}}\left(\mathrm{x}_{\mathrm{i}}, \mathrm{y}_{\mathrm{i}}\right)$ is given by:

$$
\begin{array}{r}
\mathrm{BH}_{\mathrm{i}}\left(\mathrm{x}_{\mathrm{i}}, \mathrm{y}_{\mathrm{i}}\right)=\mathrm{P}_{\mathrm{i}}\left(\mathrm{c}_{\mathrm{i}}\right)=\mathrm{P}_{\mathrm{i}}\left(\mathrm{x}_{\mathrm{i}}+\mathrm{y}_{\mathrm{i}}\right) \\
=\frac{\left[\frac{a_{\mathrm{i}}^{\mathrm{x}_{\mathrm{i}}} b_{i}^{y_{i}}}{\left(x_{i}+\mathrm{y}_{\mathrm{i}}\right) !}\right]}{\left[\sum_{j=0}^{x_{i}} \frac{a_{i}^{j}}{\mathrm{j} !}+a_{\mathrm{i}}^{\mathrm{x}_{\mathrm{i}}} \sum_{\mathrm{j}=1}^{\mathrm{y}_{\mathrm{i}}} \frac{\mathrm{b}_{\mathrm{i}}^{\mathrm{j}}}{\left(\mathrm{x}_{\mathrm{i}}+\mathrm{j}\right) !}\right]}
\end{array}
$$

\section{DYNAMIC CHANNEL RESERVATION}

In proposed DCR scheme, channel allocation is based on the new and handoff call blocking probabilities. Traffic loads are continuously varying especially in the wireless mobile networks. Since the wireless bandwidth is scarce and therefore precious. Due to the inherent bandwidth limitation in wireless cellular networks, channel allocation schemes are essentially.

The main objective of DCR scheme proposed is to give handoff calls a higher priority than new calls. To achieve this objective, handoff calls blocking probability must be preserved at the predetermined value, holding new call blocking probability as possible near to the predetermined value. DCR scheme is divided into two algorithms. The first algorithm is used to find the number of ordinary and guard channels a cell, i, based on new and handoff blocking probabilities, arrival rates $\left(\lambda_{\mathrm{i}}\right.$ and $\left.\gamma_{\mathrm{i}}\right)$ and mean holding time $(1 / \mu)$.

Herein, a pseudo code of the algorithm used to find channels, is presented.

Find-channels [Input: $\mathrm{BN}(\max ), \mathrm{BH}(\max ), \lambda_{\mathrm{i}}, \gamma_{\mathrm{i}}, \mu, \mathrm{C}_{\max }$; Output: $\mathrm{x}_{\mathrm{i}}, \mathrm{y}_{\mathrm{i}}$ ]

Begin

$$
\mathrm{i}=1 \text {; }
$$

While $\left(\mathrm{i} \leq \mathrm{N}_{\mathrm{m}}\right)$ do 
Begin

$$
\begin{aligned}
& \mathrm{a}_{\mathrm{i}}=\left(\lambda_{\mathrm{i}}+\gamma_{\mathrm{i}}\right) / \mu . ; \\
& \mathrm{b}_{\mathrm{i}}=\gamma_{\mathrm{i}} / \mu . ; \\
& \mathrm{c}_{\mathrm{i}}=1 ;
\end{aligned}
$$

While $\left(c_{i} \leq C_{\max }\right)$ do

Begin

$\mathrm{y}_{\mathrm{i}}=0$;

While $\left(\mathrm{y}_{\mathrm{i}} \leq \mathrm{c}_{\mathrm{i}}\right)$ do

Begin

$\mathrm{x}_{\mathrm{i}}=\mathrm{c}_{\mathrm{i}}-\mathrm{y}_{\mathrm{i}}$;

Compute $\mathrm{BN}_{\mathrm{i}}$ using equation (5);

Compute $\mathrm{BH}_{\mathrm{i}}$ using equation (6);

If $\left(\mathrm{BN}_{\mathrm{i}}<\mathrm{BN}_{\mathrm{i}}(\max )\right.$ AND

$\left.\mathrm{BH}_{\mathrm{i}}<\mathrm{BH}_{\mathrm{i}}(\max )\right)$ Then

Goto output;

Increment $\mathrm{y}_{\mathrm{i}}$;

End;

Increment $c_{i}$;

End;

Output: $\left(\mathrm{x}_{\mathrm{i}}, \mathrm{y}_{\mathrm{i}}\right)$;

Increment $\mathrm{i}$;

End;

End.

The second algorithm is used to assign free channels cells with low traffic load to that cells of high traffic load. This algorithm calculates, for all cells in the cluster, the previous and current values of channels in a cell $\mathrm{i}$ and calculates their summation. If this sum is a positive, it is considered as an excess channels and the cluster achieves its requirements. If it is a negative value, it means that some cells have excess channels while others suffer high traffic. Herein, a pseudo code of this algorithm is given:

Channel-assignment [Input: $\lambda_{\mathrm{i}}, \gamma_{\mathrm{i}}, 1 / \mu, \mathrm{BN}_{\mathrm{i}}(\max ), \mathrm{BH}_{\mathrm{i}}(\max ), \mathrm{C}_{\mathrm{i}}(\max ), \mathrm{N}_{\mathrm{m}}$, limit, Deg_Factor; Output: $\mathrm{x}_{\mathrm{i}}, \mathrm{y}_{\mathrm{i}}, \mathrm{c}_{\mathrm{i}}$ ]

Begin

$\mathrm{i}=1$;

While $\left(\mathrm{i} \leq \mathrm{N}_{\mathrm{m}}\right)$ do

Begin

Find-channels [Input: $\mathrm{BN}_{\mathrm{i}}(\max ), \mathrm{BH}_{\mathrm{i}}(\max ), \lambda_{\mathrm{i}}($ new $), \gamma_{\mathrm{i}}($ new $), 1 / \mu, \mathrm{C}_{\mathrm{i}}(\max )$; Output: $\mathrm{x}_{\mathrm{i}}$ (cur), $\mathrm{y}_{\mathrm{i}}$ (cur), $\quad \mathrm{BN}_{\mathrm{i}}($ cur $), \mathrm{BH}_{\mathrm{i}}($ cur $\left.)\right]$;

$\mathrm{c}_{\mathrm{i}}($ cur $)=\mathrm{x}_{\mathrm{i}}($ cur $)+\mathrm{y}_{\mathrm{i}}($ cur $)$;

$\Delta \mathrm{c}_{\mathrm{i}}=\mathrm{c}_{\mathrm{i}}-\mathrm{c}_{\mathrm{i}}($ cur $)$;

pool $=$ pool $+\Delta \mathrm{c}_{\mathrm{i}}$

Increment $\mathrm{i}$;

End;

If $($ pool $\geq 0)$ then Excess = pool;

$\Delta \mathrm{c}_{\mathrm{i}}$-final $=0$; 


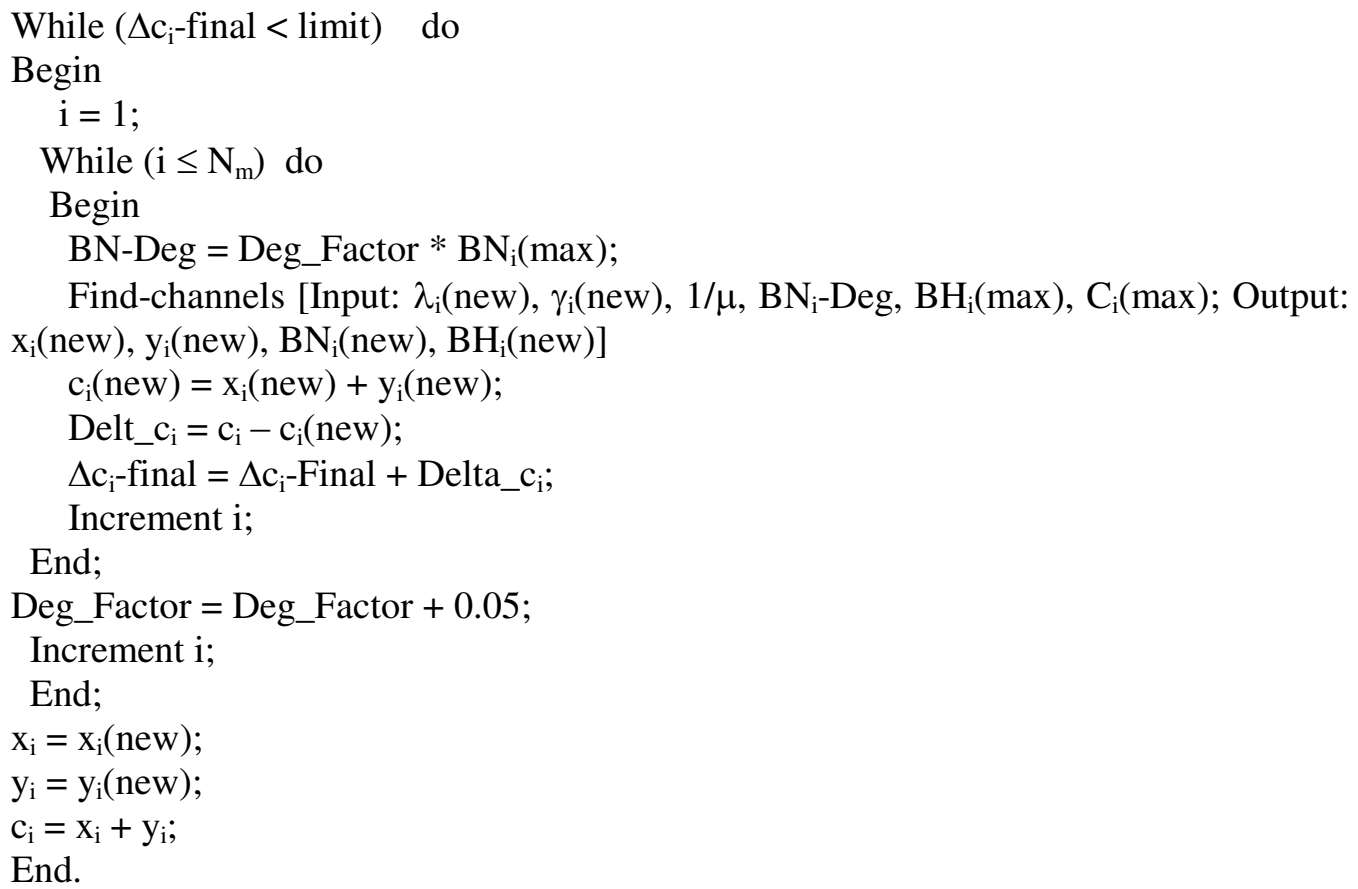

\section{PERFORMANCE EVALUATION}

The new call blocking probability $\mathrm{BN}$ and the handoff dropping probability $\mathrm{BH}$ are defined as the system performance metrics. In order to evaluate the proposed DCR scheme, various values of new and handoff blocking probabilities are taken. Also different values of ordinary and guard channels assigned to cells are considered. Different limit values (a minimum value of cells exist in the pool) and their effect on handoff calls performance are taken into account.

Figure 1 shows the number of ordinary channels x per cell with/without applying DCR scheme. It can be shown that channels needed for cells 7, 11 and 12 are increased to achieve the required $\mathrm{GoS}(\mathrm{BN}=1.44 \mathrm{e}-2$ and $\mathrm{BH}=2.2 \mathrm{e}-3)$ of both types of calls.

Also, it can be observed that the number ob channels at cells 8 and 10 and 14 is decreased which mains that these cells have an excess of channels. Figure 2 shows the effect of DCR on the guard channels y. From Figure 2 it can be observed that guard channels are increased almost by one channel to improve handoff blocking probability using proposed scheme.

Figure 3 shows the performance of DCR scheme on handoff blocking probabilities experienced by the system. From Figure 3(a) it can be shown that the current handoff blocking probability (BH_cur) is greater than the required (maximum) one. The handoff blocking probability at cells 7 and 11 are about $3.8 \%$ and $7 \%$, respectively. Applying DCR scheme improves these blocking probability. It is seen, for cell 11, that the blocking probability decreases from $6.53 \%$ to $0.077 \%$, while it decreases for cell 7 , from $3.8 \%$ to $0.073 \%$. 


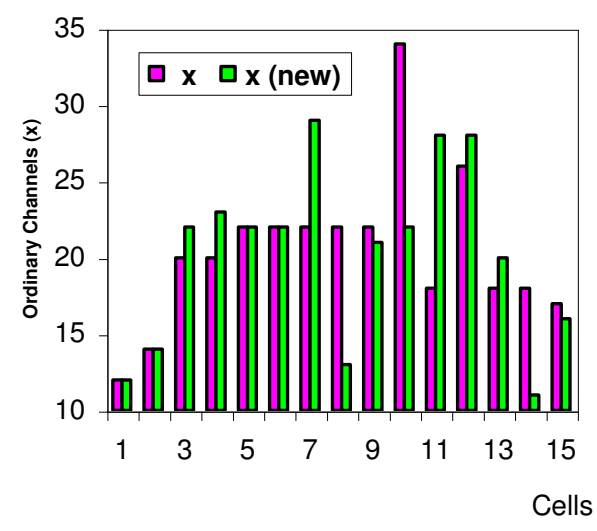

Fig. 1: Ordinary Channels against Cells.

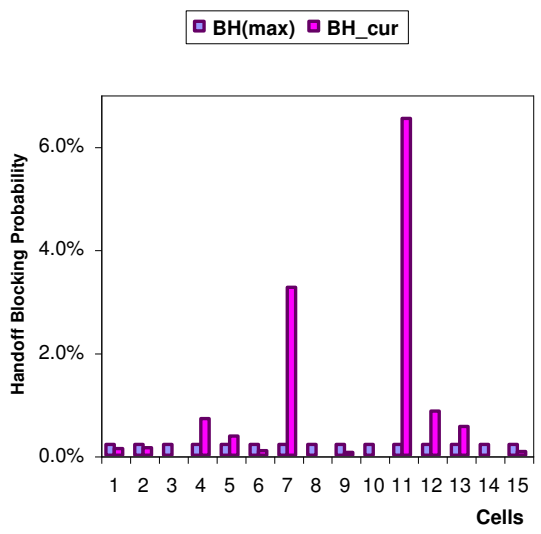

(a) without DCR.

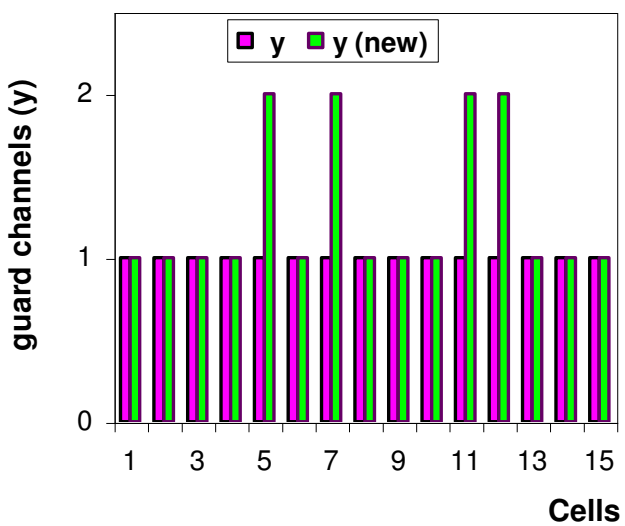

Fig. 2: Guard Channels against Cells.

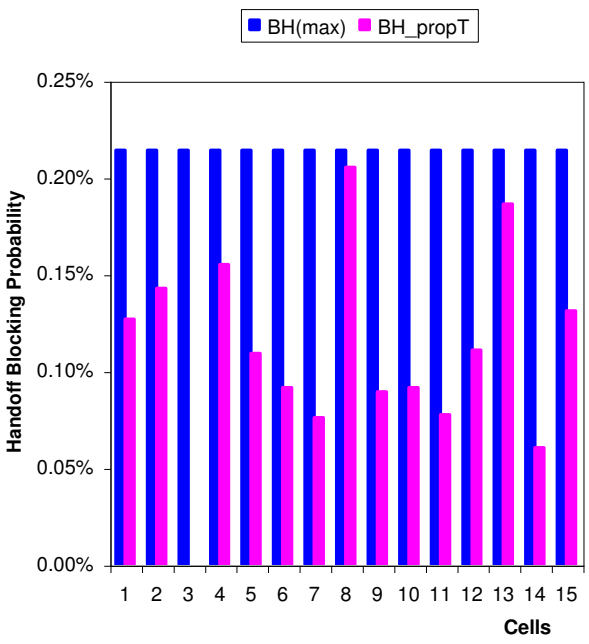

(b) using DCR.

Fig. 3: Performance of DCR Scheme on Handoff Calls.

It can be observed from Figure 4 (a) that the current new call blocking probability (BN_cur) is much greater than the maximum value. For example, they have the values $5 \%, 15 \%$ and $27 \%$ at cells 3,7 and 11, respectively. From Figure 4 (a) and (b), it is seen that new call blocking probability, for cell 11, decreases from $27 \%$ to $2.3 \%$ (remember that ordinary channels of this cell was increased from 18 to 28 channels), which can be acceptable. The same results are shown for cells 3 and 7. Also, it can be observed that blocking probability is improved for cells 4,12 and 13. It can be observed that blocking probability at cells 5, 8, 9, 10 and 15 is increased slightly. So, it 
can be said that the improvement in handoff and new calls of some cells in the system is on the expense of some increment of blocking in another cells.

Figure 5 compares the performance of DCR scheme at different values the limit factor. This Figure shows that as limit increases, blocking probability degradation increases. It can be observed that using a limit of value 3 , the new calls blocking probability will be $2.7 \%$ (at cell 5), While this value is $1.6 \%$ using a limit value of 0 or 1 . Also, it is shown that blocking probability at cell 13 is the same for the three values of limit.

BN (max) $\square$ BN_DegT
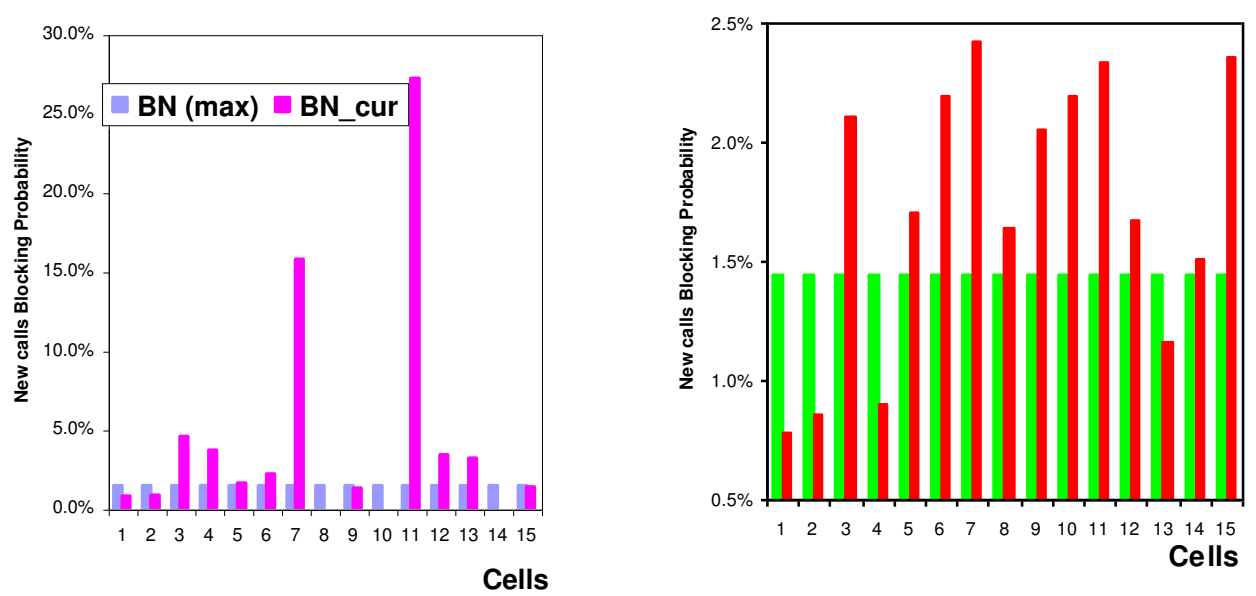

(a) without DCR.

(b) using DCR.

Fig. 4: Performance of DCR Scheme on New Calls.

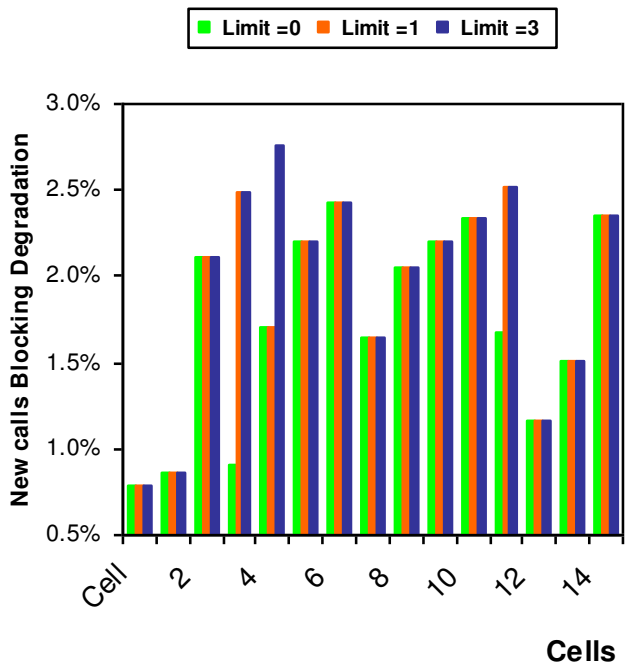

Fig. 5: Limit Factor Effect on New Calls Blocking Probability. 


\section{CONCLUSION}

A new DCR scheme is proposed for handoff prioritization which is based on the new and handoff calls blocking probabilities. This scheme uses the concept of reservation pooling to improve the channel utilization of the cellular systems. Extensive simulations were performed, and the simulation results show that, the proposed DCR scheme can improve the handoff calls blocking probability while maintaining an acceptable value of new calls blocking probability.

\section{REFERENCES}

[1] P. Todorova, S. Olario, and H. N. Nguyen,"A Two-cell-look ahead call admission and handoff management scheme for multimedia Leo satellite networks," IEEE Proceeding of the $36^{\text {th }}$ Hawaii International Conference on System Sciences, pp. 1-9, 2003.

[2] S. Tekinay and B. Jabbari,"Handover policies and channel assignment strategies in mobile cellular networks," IEEE Communications Magazine Vol. 29, No. 11, 1991.

[3] N. D. Tripathii, J. H. Reed and H. F. Vanlandinoham," Handoff in cellular systems," IEEE Personal Communications Vol. 5, No. 6, Dec. 1998.

[4] D. Hong and S. S. Rappaport,"Traffic model and performance analysis for cellular mobile radio telephone systems with prioritized and nonprioritized handoff procedures," IEEE Trans. On Veh. Tech. Aug 1986.

[5] Y. C. Kim, D. E. Lee, B. J. Lee, and Y. S. Kim, "Dynamic channel reservation based on mobility in wireless ATM networks," IEEE Communication Magazine, Nov. 1999.

[6] O. T. Yu and V. C. M. Leung, "Adaptive resource allocation for prioritized call admission over an ATM-based wireless PCN," IEEE Journal on Selected Area in Communications, Vol. 15, No. 7, September 1997.

[7] M. H. Chiu and Mostafa. A. Bassiouni, "Predictive schemes for handoff prioritization in cellular networks based on mobile positioning," IEEE Journal on Selected Areas in Communications, Vol.18, No.3, March 2000.

[8] W. Zhuang, K. C. Chua and S. M. Jiang, "Measurement-based dynamic bandwidth reservation scheme for handoff in mobile multimedia networks," IEEE 1998 International Conference on Universal Personal Communications.

[9] Carolin I. Bauer, Dr. S. John Rees, "Classification of handover schemes within A cellular environment," PIMRC 2002.

[10] S. Choi and G. Shin, "Predictive and adaptive bandwidth reservation for hand-offs in QoS-sensitive cellular networks," in Proc. ACM SIGCOMM' 98, pp. $155-166$. 


\section{المخطط الايناميكي لحجز القنوات للمكالمات المنقولة في الثبكات اللاسلكية الخلوية الفيكات}

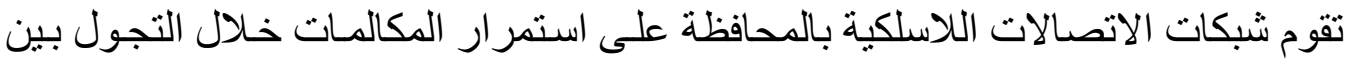

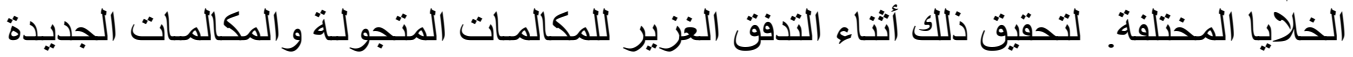

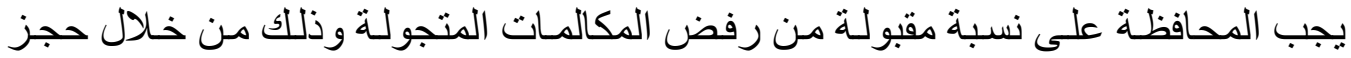

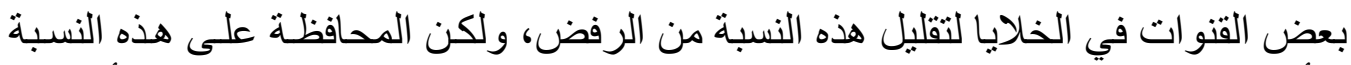

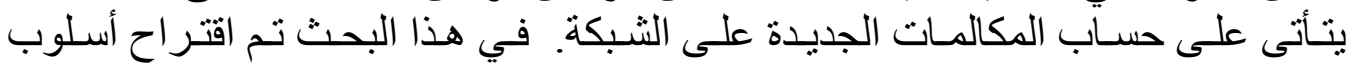

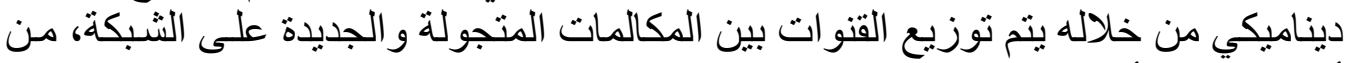

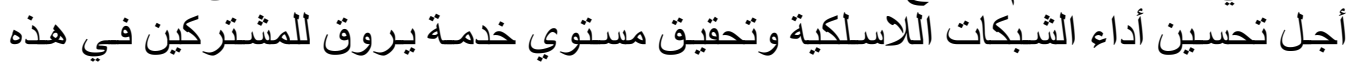

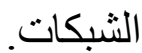

